\title{
DIURNAL VARIATIONS OF RENAL FUNCTION IN MAN
}

\author{
By JONAS H. SIROTA,1 DAVID S. BALDWIN,2 AND HERMAN VILLARREAL ${ }^{3}$ \\ (From the Departments of Physiology and Medicine, New York University College of Medicine, \\ New York, New York)
}

(Received for publication July 18,1949 )

A diurnal rhythm in water and electrolyte excretion in man has been described by several investigators. Kleitman (1) reported decreased urine flow and chloride excretion during sleep as compared to "waking" hours, and suggested decreased blood pressure during sleep as the cause. Simpson $(2,3)$ confirmed these observations in young healthy adults who ingested the same amount of water at hourly intervals throughout 24 hours and suggested the acidosis of sleep, with the resultant intracellular shift of chloride and water, as a possible mechanism for the positive balance of these substances during sleep. Manchester (4) studied the 24 hour variations of water and mineral balance in two epileptic children on graded activity. He found that the maximum excretion of water, sodium, potassium and chloride occurred from 6:00 A.M. to 12:00 midnight, the minimum excretion from 12 midnight to $6: 00$ A.M. He concluded that the diurnal variation of water and mineral excretion is related to sleep rather than to changes in physical activity. Simpson (5) was unable to affect the cycle by means of dehydration, fasting, changes in posture or short periods of sleep during the day. Norn (6) reported a reversal of the cycle with respect to time in a night watchman who obtained his normal complement of sleep during the day. Brod (7) showed that normal subjects have depressed endogenous "creatinine" clearances at night associated with diminished urine flow.

It has been adequately demonstrated that the diurnal rhythm in water and electrolyte excretion may be absent or reversed in pathologic states. Fishberg (8) states that the nocturia of nephritis is due to a lack of concentrating ability and that this symptom in hypertension may be due to this

\footnotetext{
1 Sarah Welt Fellow. Present address : Department of Medicine, The Mount Sinai Hospital, New York City.

2 Present address : Department of Medicine, New York University College of Medicine, New York, New York.

${ }^{\mathbf{3}}$ Rockefeller Foundation Fellow. Permanent address: National Institute of Cardiology, Mexico City, Mexico.
}

renal factor or to an increase in cardiac output in the prone position. In heart failure (9) the nocturia is explained on the basis of increased cardiac output and decreased renal venous pressure in the prone position. Brod (7), using the endogenous "creatinine" clearance as a measure of glomerular filtration and the "creatinine" $U / P$ ratio as an indication of tubular reabsorption of water, demonstrated that the nocturia of congestive failure is associated with both a rise in glomerular filtration and decreased tubular reabsorption of water during sleep. In glomerulonephritis, however, the nocturia was due primarily to decreased water reabsorption, the filtration rate remaining fairly constant throughout 24 hours. Breed and Schreiner (10) have shown that some patients with essential hypertension have nocturia associated with a reversal of the normal diurnal pattern for chloride excretion and endogenous "creatinine" clearance.

Because of the obscurity of the mechanism controlling this diurnal cycle of salt and water excretion and its importance in the treatment of congestive heart failure we have undertaken a study of the 24 hour variations of renal hemodynamics in normal subjects and in subjects with congestive heart failure. The present paper deals with normal subjects alone.

\section{METHODS}

Simultaneous endogenous "creatinine," inulin and paminohippurate, free and total (free plus conjugated), clearances were determined in 18 normal male subjects during four to six hour periods throughout 24 to 48 hours. The subjects were all convalescent patients without clinical evidence of cardiovascular-renal disease. They were maintained at bed rest for at least 24 hours prior to as well as during the period of observation. They were on routine ward diets and were allowed fluids ad lib.

The test substances were delivered by means of a constant delivery pump at rates varying from 0.20 to 0.50 $\mathrm{cc} / \mathrm{min}$. in 14 of the subjects. For the first three a pusher type pump was used in which the plunger of a $100 \mathrm{cc}$. syringe, filled with the sustaining infusion, was slowly driven forward by a synchronized motor through a geared-down worm-screw drive. When empty the syringe 
was refilled by gravity through a three-way stopcock. Seven experiments were performed with a mercury gravity pump, delivery being accomplished by means of a fine flow of mercury through a capillary tube (thermometer tubing) into an air-free, air-tight pressure flask displacing the sustaining infusion contained therein through the side arm. The mercury was sterilized by placing it in boiling water for 20 minutes followed by passage through a column of 70 per cent alcohol. Analyses of infusion fluids so maintained in contact with metallic mercury for 48 hours contained no detectable traces of dissolved mercury (up to one part per million). The rate of delivery was obtained either indirectly by weighing the flask at stated intervals, thus

$$
\text { cc./min. }=\frac{\text { gms. }}{\min .} \text { (sp. gr. } \mathrm{Hg}-\text { sp. gr. infusion), }
$$

or directly by means of a calibrated rotameter (11). A milking type of pump, with synchronized finger-like prongs which sequentially compress a piece of rubber tubing coupling the infusion mixture and the patient, was used in the last four pump experiments. ${ }^{4}$ In four subjects the infusion was delivered by a simple gravity drip, employing a tunnel clamp for flow regulation. With the exception of two runs, in which leaks in the system were present, the blood levels of inulin and PAH obtained with these methods of infusion were more constant over a 24 hour period than is usually found in short-term observations using a gravity drip. The clearances were calculated by both the pump technique of Earle and Berliner (12), in which $\frac{\text { IV }}{\mathrm{P}}\left(\frac{\text { rate of infusion of substance }}{\text { plasma concentration }}\right)$ is equated to $\frac{\mathrm{UV}}{\mathrm{P}}$ at constant blood levels, and by the standard urine collection techniques. For this comparison the clearance of total (free plus conjugated) $\mathrm{PAH}$ was used.

The sustaining infusions were made up in either normal saline or 5 per cent glucose, ${ }^{5}$ containing $0.1 \mathrm{mgm}$. heparin /cc. They were delivered through a thin plastic intravenous catheter supplied by L. H. Peterson (13), which

4 This pump was designed and built by Dr. Robert Bowman, of the Department of Medicine, New York University College of Medicine, and was found most suitable for our purposes. The infusion rate may be varied from approximately 0.25 to $7.5 \mathrm{cc} . / \mathrm{min}$. in $12 \mathrm{steps}$, the exact flow depending upon the nature of the rubber tubing used. Delivery is pulsatile and has an error of approximately \pm 2.0 per cent at $0.5 \mathrm{cc} . / \mathrm{min}$. for 30 minute periods. This error decreases proportionately with increase in length of period. Process and Instruments Co., 60 Greenpoint Avenue, Brooklyn 22, New York, are preparing to make this pump available on a commercial basis.

- Five per cent glucose in distilled water was used as a diluent for the sustaining infusion in seven instances. The PAH clearance values obtained with this diluent were found to be invalid for reasons which will be reported subsequently. All data on PAH clearances performed with the glucose solution as a diluent are therefore deleted from the present report. was passed through a wide-bored needle (No. 15 or 16) to the level of the subclavian vein in accordance with the technique described by Ladd and Schreiner (14). After insertion of the catheter the needle was removed and the distal end of the catheter was snugly adapted to one of slightly wider bore which in turn was connnected to the rubber tubing leading from the infusion flask.

The clearance periods were four hours long during the day and of four or six hours duration at night. The sleeping hours were approximately from 8:00 P.M. to 6:00 A.M. Urine was collected by spontaneous voiding and bloods were drawn approximately at the midpoint of each urine collection period. Patients over 50 were tested for bladder urine residual after voluntary voiding before the onset of the clearance determinations. Significant residual urine was found in patients $C$. H. and $R$. W., aged 74 and 68 respectively. In these subjects retention catheters and bladder washouts were used. Little difficulty with bladder emptying was experienced in the remainder of the subjects when awakened at night. Renal vein catheterization was performed on two subjects using the technique of Warren, Brannon and Merrill (15) and Bradley and Bradley (16) in order to determine the renal extraction ratios of $\mathrm{PAH}$ after a constant 24 hour infusion of this substance. ${ }^{6}$ Plasma concentrations were plotted semilogarithmically against time and the representative concentrations extrapolated from the midpoint of each urine collection period.

Inulin was determined by a modification of Harrison's method as described by Goldring and Chasis (17). The urines as well as the plasma specimens were yeasted, minimizing errors which might be introduced by changing "inulin blanks." Creatinine was determined by the Bonsnes and Taussky method (18) and p-aminohippurate, free and conjugated, by the method of Smith et al. (19).

All subjects were patients from the wards of the Third (New York University) Medical or Surgical Services of Bellevue Hospital.

\section{RESULTS}

\section{Diurnal variations of function}

The day and night functions, including urine flow, inulin $U / P$ ratio (tubular reabsorption of water), $\mathrm{C}_{\mathrm{IN}}, \mathrm{C}_{\mathrm{CR}}$ and $\mathrm{C}_{\mathbf{P A H}_{F}}{ }^{7}$ are compared for individual subjects in Table $\mathrm{I}$. The night value in each case represents the mean value obtained for the periods corresponding roughly to the sleeping hours for that individual; the day values are the means of all other observations. The

- Renal catheterization and analyses were performed by Drs. Ernest Breed and Morton Maxwell.

7 The following abbreviations will be used: $\mathrm{C}_{\mathrm{IN}}=$ inulin clearance, $\mathrm{C}_{\mathrm{CR}}=$ endogenous "creatinine" clearance, $\mathrm{E}_{\mathrm{PAB}}$ $=$ extraction ratio of $p$-aminohippurate, inulin $U / P$ ratio = ratio of inulin concentrations in urine and plasma, N/D $=$ night/day ratio, $\mathrm{V}=$ urine flow, $\mathrm{C}_{\mathrm{PAH}_{\mathrm{F}}}=$ clearance of free PAH. 
TABLE I

Comparison of values obtained for $V, U / P$ ratio for irulin, $C_{I N}, C_{C R}$ and $C_{P A H}$ durirg the waking and sleeping hours in 18 normal male subjects. All clearance data are corrected for a body surface area of $1.73 \mathrm{sq} . \mathrm{m}$.

\begin{tabular}{|c|c|c|c|c|c|c|c|c|c|c|c|c|c|c|c|c|c|c|c|c|}
\hline \multirow{3}{*}{$\underset{\text { tient }}{\mathrm{Pa}-}$} & \multirow{3}{*}{ Age } & \multirow{2}{*}{\multicolumn{2}{|c|}{$\begin{array}{c}\text { Average } \\
\text { urine flow }\end{array}$}} & \multirow{2}{*}{\multicolumn{2}{|c|}{$\begin{array}{l}\text { Average inu- } \\
\text { lin U/P ratio }\end{array}$}} & \multicolumn{6}{|c|}{ Average clearance } & \multirow{2}{*}{\multicolumn{5}{|c|}{$N / D$ ratios }} & \multirow{3}{*}{$\frac{C_{C R}}{C_{I N}}$} & \multirow{2}{*}{\multicolumn{2}{|c|}{$\mathrm{C}_{\text {IN }} / \mathrm{C}_{\mathrm{PAB}}$}} & \multirow{3}{*}{$\mathbf{E}_{\mathbf{P A}} \mathbf{P}$} \\
\hline & & & & & & \multicolumn{2}{|c|}{ Inulin } & \multicolumn{2}{|c|}{ Creatinine } & \multicolumn{2}{|c|}{ PAHF } & & & & & & & & & \\
\hline & & Day & Night & Day & Night & Day & Night & Day & Night & Day & Night & $\begin{array}{l}\text { Urine } \\
\text { flow }\end{array}$ & Inulin & $\mathrm{C}_{\mathrm{IN}}$ & $\mathrm{C}_{\mathrm{CR}}$ & $\mathrm{C}_{\mathrm{PAB}} \mathbf{F}$ & & Day & Night & \\
\hline $\begin{array}{l}\text { G.W. W. } \\
\text { H. J. } \\
\text { W. B. } \\
\text { H. s. } \\
\text { J.C. } \\
\text { P. R. } \\
\text { D.W. } \\
\text { G.F. } \\
\text { P. M. } \\
\text { N.W. W. } \\
\text { R. V. } \\
\text { F. E. } \\
\text { M. R. } \\
\text { C. H. } \\
\text { R.W. } \\
\text { J. B. } \\
\text { J. F. } \\
\text { J. M. }\end{array}$ & \begin{tabular}{|c|}
$\mid y r s$. \\
24 \\
47 \\
37 \\
49 \\
20 \\
28 \\
22 \\
33 \\
43 \\
47 \\
25 \\
50 \\
18 \\
74 \\
68 \\
52 \\
49 \\
42
\end{tabular} & \begin{tabular}{|c|}
$c c$. \\
$\min$. \\
3.17 \\
5.11 \\
5.02 \\
1.74 \\
2.29 \\
1.72 \\
1.98 \\
3.21 \\
1.39 \\
2.68 \\
1.99 \\
0.56 \\
2.88 \\
0.71 \\
0.63 \\
1.31 \\
3.24 \\
2.57
\end{tabular} & $\begin{array}{l}c c . f \\
\text { min. } \\
2.91 \\
3.10 \\
2.07 \\
1.58 \\
1.25 \\
1.49 \\
1.76 \\
1.57 \\
1.32 \\
1.53 \\
1.31 \\
0.82 \\
0.94 \\
0.60 \\
1.23 \\
1.27 \\
2.36 \\
2.14\end{array}$ & \begin{tabular}{|c}
50.3 \\
32.5 \\
$45.2 *$ \\
$60.5 *$ \\
52.5 \\
104 \\
64.4 \\
42.3 \\
98.5 \\
40.8 \\
64.1 \\
169 \\
57.6 \\
108 \\
120 \\
69.2 \\
29.9 \\
39.1
\end{tabular} & \begin{tabular}{|c|}
78.4 \\
41.9 \\
$64.1^{*}$ \\
$65.4^{*}$ \\
103 \\
130 \\
76.1 \\
88.3 \\
104 \\
77.3 \\
97.1 \\
147 \\
97.1 \\
139 \\
61.6 \\
74.8 \\
66.2 \\
54.1
\end{tabular} & $\begin{array}{c}c c . / \\
\text { min. } \\
125 \\
122 \\
\\
158 \\
146 \\
121 \\
117 \\
120 \\
117 \\
106 \\
115 \\
126 \\
69.0 \\
72.5 \\
103 \\
99.0 \\
109\end{array}$ & \begin{tabular}{|l}
$c c . /$ \\
min. \\
121 \\
109 \\
\\
153 \\
146 \\
109 \\
110 \\
117 \\
108 \\
104 \\
115 \\
99.0 \\
70.2 \\
82.0 \\
100 \\
96.0 \\
103
\end{tabular} & \begin{tabular}{|l|}
$c c . /$ \\
$\min$. \\
135 \\
141 \\
91.3 \\
136 \\
149 \\
122 \\
110 \\
81.8 \\
102 \\
99 \\
102 \\
75.5 \\
79.2 \\
87.2 \\
106
\end{tabular} & \begin{tabular}{|c}
$c c . /$ \\
$\min$. \\
130 \\
139 \\
98.3 \\
135 \\
142 \\
107 \\
104 \\
86.5 \\
85.0 \\
100 \\
91.0 \\
76.4 \\
79.3 \\
88.0 \\
97.5
\end{tabular} & $\begin{array}{l}c c . / \\
\text { min. } \\
732 \\
687 \\
500 \\
884 \\
664 \\
761 \\
488 \\
588\end{array}$ & $\begin{array}{c}c c . / \\
\min . \\
686 \\
610 \\
528 \\
934 \\
636 \\
691 \\
462 \\
608\end{array}$ & $\begin{array}{l}0.92 \\
0.61 \\
0.41 \\
0.91 \\
0.55 \\
0.87 \\
0.89 \\
0.49 \\
0.95 \\
0.57 \\
0.66 \\
1.48 \\
0.33 \\
0.85 \\
1.95 \\
0.97 \\
0.73 \\
0.83\end{array}$ & $\begin{array}{l}1.55 \\
1.29 \\
1.42 \\
1.08 \\
1.96 \\
1.25 \\
1.20 \\
2.08 \\
1.03 \\
1.88 \\
1.52 \\
0.87 \\
1.68 \\
1.28 \\
0.51 \\
1.08 \\
2.21 \\
1.38\end{array}$ & $\begin{array}{l}0.97 \\
1.00 \\
0.90 \\
0.94 \\
0.98 \\
0.92 \\
0.98 \\
1.00 \\
0.79 \\
1.02 \\
1.13 \\
0.97 \\
0.97 \\
0.94\end{array}$ & $\begin{array}{l}0.96 \\
0.92 \\
1.08 \\
0.99 \\
0.96 \\
0.87 \\
0.95 \\
1.06 \\
0.03 \\
1.01 \\
0.89 \\
1.01 \\
1.00 \\
1.01 \\
0.92\end{array}$ & $\begin{array}{l}0.94 \\
0.89 \\
1.06 \\
1.06 \\
0.96 \\
0.91 \\
0.95 \\
1.02\end{array}$ & $\begin{array}{l}0.87 \\
1.00 \\
1.00 \\
0.94 \\
0.75 \\
0.91 \\
0.86 \\
0.87 \\
1.09 \\
1.03 \\
0.88 \\
1.04\end{array}$ & $\begin{array}{l}0.17 \\
0.21 \\
0.18 \\
0.18 \\
0.22 \\
0.16 \\
0.25 \\
0.20 \\
\\
\\
0.19 \\
0.19\end{array}$ & $\begin{array}{l}0.18 \\
0.23 \\
0.19 \\
0.17 \\
0.22 \\
0.15 \\
0.25 \\
0.19\end{array}$ & $\begin{array}{l}.903 \\
.930\end{array}$ \\
\hline & & & & & & & & & & & $\begin{array}{l}\mathbf{M} \\
\text { S.D. }\end{array}$ & $\begin{array}{r}0.83 \\
\pm 0.38\end{array}$ & $\begin{array}{r}1.40 \\
\pm 0.41\end{array}$ & $\begin{array}{r}0.96 \\
\pm 0.07\end{array}$ & $\begin{array}{r}0.97 \\
\pm 0.06\end{array}$ & $\begin{array}{r}0.98 \\
\pm 0.06\end{array}$ & $\begin{array}{r}0.95 \\
\pm 0.10\end{array}$ & & & \\
\hline
\end{tabular}

*Inulin clearances were not performed on these subjects. The values given are endogenous "creatinine" U/P ratios. All urine flow figures, $U / P$ ratios and clearance values represent average values obtained from several clearance periods. This explains the apparent discrepancy between the given values for clearance (UV/P) and those which would be obtained by the product of the average values for $V$ and $U / P$.

TABLE II

Mean values for $C_{I N}, C_{C R}, C_{P A H_{F}}, V, U / P$ ratio for inulin and filtration fraction at four hour intervals as obtained from the pooled data of all the normal subjects. All clearance data are corrected for a body surface area of $1.73 \mathrm{sq} . \mathrm{m}$.

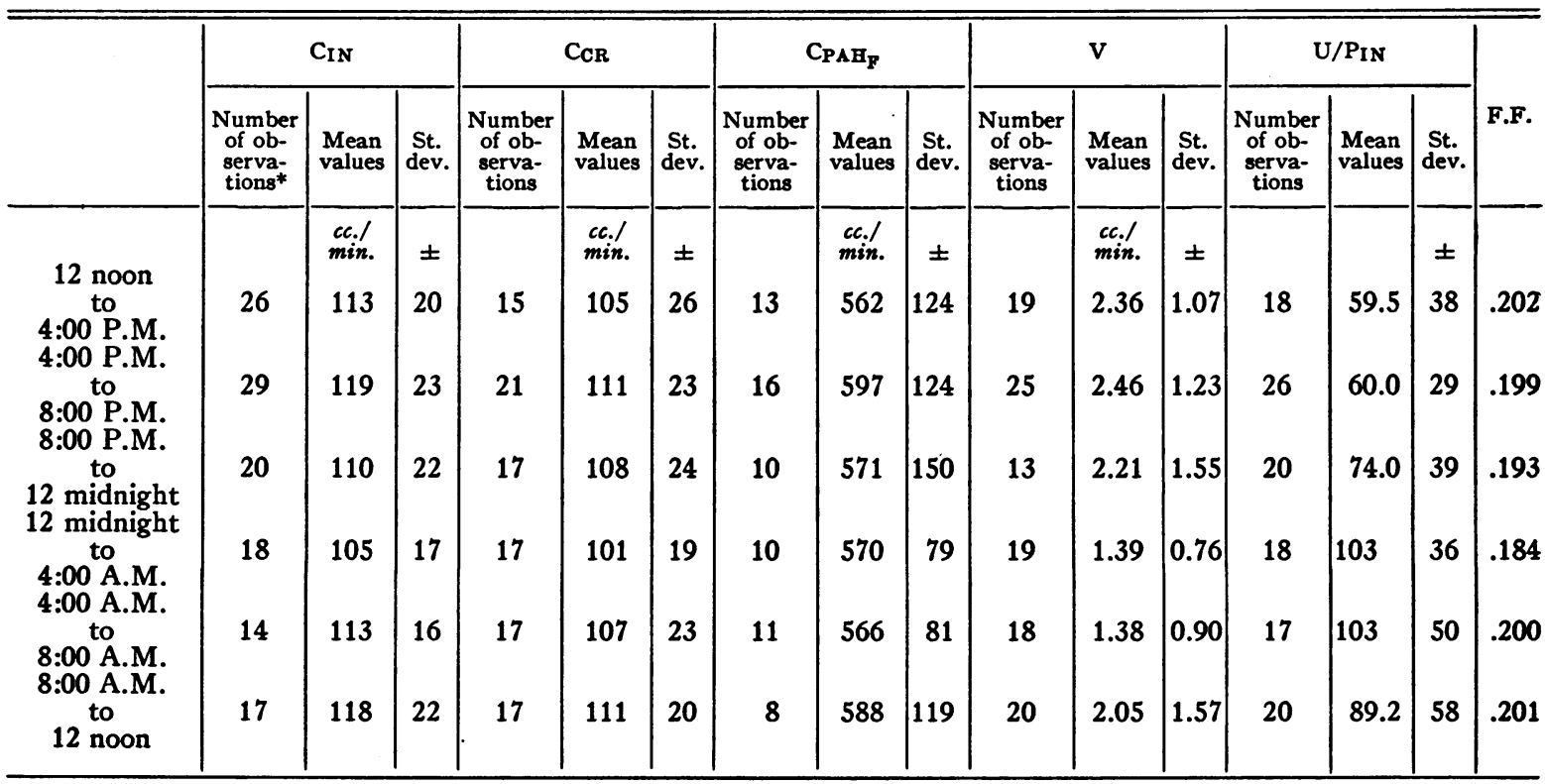

* The greater number of observations during the day is due to the continuation of some of the studies for more than 24 hours but less than 48 . 
night/day (N/D) ratios for these functions therefore represent the ratios of the "sleeping" to "waking" values.

In all but two individuals, F. E. and R. W., there was a drop in urine flow during sleep, with a mean $\mathrm{V} \mathrm{N} / \mathrm{D}$ ratio of $0.83 \pm 0.38$ and a rise in tubular reabsorption of water, with a mean inulin $U / P N / D$ ratio of $1.40 \pm 0.41$. Subject F. E. was somewhat oliguric during the period of observation for unknown reasons, and R. W. was a 68 year old man with depressed glomerular filtration. The $C_{I N} N / D$ ratios, with the exception of two subjects, were all at or slightly below 1.00 , with a mean value of $0.96 \pm 0.07$. The $C_{C R} N / D$ ratios revealed a similar general pattern, with a mean of $0.97 \pm 0.06$. It is of interest that the two subjects with $C_{I N} N / D$ ratios greater than 1.00 , C. H. and R. W., were both older men, 74 and 68 respectively, with depressed filtration rates. The $\mathrm{C}_{\mathrm{PAB}_{\mathrm{F}}} \mathrm{N} / \mathrm{D}$ ratio revealed no consistent pattern, with a small scatter about 1.00 , the mean being $0.98 \pm 0.06$. There was no systematic change in N/D ratio of either $C_{I N}, C_{C R}$ or $C_{P_{A A}}$ with the absolute value of these functions.

For the purpose of statistical analysis of the 24 hour fluctuations of function other than that which occurs during sleeping and waking hours, the data were pooled into six four hour periods, regardless of individual fluctuations, and all clearance values corrected to an ideal surface area of $1.73 \mathrm{sq} . \mathrm{m}$. The mean values obtained by such a grouping are presented in Table II and Figure 1. It appears that the greatest change in function (fall in filtration and urine flow and increase in water reabsorption) appears from 12 midnight to 4:00 A.M., the period corresponding to deepest sleep. This change is statistically significant for urine flow and water reabsorption and is just within the limits of statistical significance for filtration rate. ${ }^{8}$ A significant fall in $\mathrm{C}_{\mathbf{P A H}}$ is not present. The filtration fraction therefore falls correspondingly.

With the exception of N. W., the mean endogenous "creatinine" clearances checked well with the mean inulin clearances, the mean $\mathrm{C}_{\mathrm{CR}} / \mathrm{C}_{\mathrm{IN}}$ ratio being $0.95 \pm 0.10$.

8 The significance ratio of $\mathrm{C}_{\mathrm{IN}}$ of $105 \mathrm{cc} . / \mathrm{min}$. during the 12 to $4: 00$ A.M. period as compared to $119 \mathrm{cc} . / \mathrm{min}$. in the $4: 00$ to $8: 00$ P.M. period is 2.23 , making the probability about 40 to one against this being a chance difference.

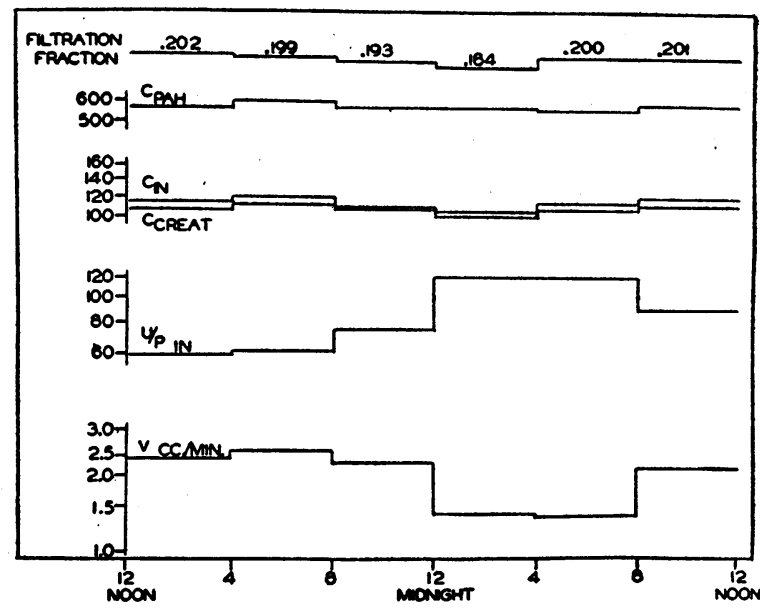

Fig. 1. Graphic Representation of the 24 Hour Variations of V, U/P for Inulin, $C_{\text {in, }} C_{\text {CR, and }} C_{\text {Pat }}$ at Four Hour Intervals in 18 Normal Male Subjects AT Bed REST

The values used are the means of the pooled data. $\mathrm{V}$ is depressed and $U / P$ for inulin elevated to statistically significant values during the sleeping hours. The depressions of $C_{I N}$ and $C_{C R}$ during the 12 midnight to 4:00 A.M. period are just within the limits of statistical significance. Significant variations of $\mathrm{C}_{\mathrm{PAB}}$ do not occur.

$\mathrm{E}_{\mathrm{PAH}_{\mathrm{F}}}$ determined in two subjects, J. F. and J. M., after 24 hours of sustaining infusion revealed values of 0.903 and 0.930 , indicating continued normal extraction of $\mathrm{PAH}$ in spite of prolonged infusion of this substance, validating $\mathbf{C}_{\mathbf{P A B}_{\mathbf{P}}}$ as a measure of effective renal plasma flow in these prolonged techniques.

\section{Comparison of pump and bladder clearance tech- niques}

Measurement of glomerular filtration rate and renal plasma flow, utilizing inulin and $\mathrm{PAH}$, were determined by simultaneous pump and urine collection techniques in 10 patients during the course of the 24 hour studies. With the exception of one patient, there was a poor correlation between the two methods, the clearances calculated by the pump method being usually 10 per cent or more above those values obtained by means of urine collection. The reason for this discrepancy is not apparent. It may be related to the use of the concentrated sustaining solution necessary at rates of infusion as low as 0.2 to $0.5 \mathrm{cc}$. $/ \mathrm{min}$. (approximately 8 and 5 per cent, respectively, for inulin and $\mathrm{PAH}$ ). Small volume losses and small changes in infusion 
rates would therefore introduce considerable errors.

\section{DISCUSSION}

Our observations reveal that in adult males without cardiovascular-renal disease, at bed rest, glomerular activity remains relatively constant throughout 24 hours with the exception of slight depression during deep sleep. In confirmation of the results of previous investigators we have found a significant depression of urine flow at night, which is maximal between 12 midnight and 4:00 A.M. That this depression is due primarily to increased tubular reabsorption of water rather than hemodynamic factors is shown by the marked increase in the inulin $U / P$ ratios during this period of maximal urine suppression. Simpson (2) has shown that this phenomenon occurs even if the fluid intake at night equals that of the day.

Renal plasma flow under our conditions of examination remains constant throughout the 24 hour period, resulting in a slightly decreased filtration fraction during deep sleep.

It is very likely that significant changes in renal plasma flow occur throughout the day in response to various physiological functions, such as eating, straining at stool, etc. However, such variations are apparently of brief duration and are not reflected in four hour clearance periods while at bed rest. The normal mean values for glomerular filtration rate and effective renal plasma flow at their peak levels were $119 \pm 23$ and $597 \pm 124 \mathrm{cc} . / \mathrm{min}$. per 1.73 sq.m., respectively. They are considerably lower than the values of $131 \pm 22$ and $697 \pm$ $136 \mathrm{cc} . / \mathrm{min}$. per $1.73 \mathrm{sq}$. m. cited by Goldring and Chasis (17). The reason for these differences is not obvious, but may be attributable to the fact that the observations upon which the latter figures are based were short period observations made in the post-absorptive state and at high urine flows.

Brod and Sirota (20) have shown that $C_{C R}$ may be used as a good measure of glomerular activity for short period observations in subjects without renal disease. In view of the excellent agreement between $C_{I N}$ and $C_{C R}$ throughout 24 hours $C_{C R}$ may be used for measuring glomerular activity in such subjects for prolonged periods as well. ${ }^{\circ}$

\footnotetext{
9 Preliminary observations in patients with congestive heart failure suggest that a discrepancy between $C_{C R}$ and $C_{I N}$ may exist in this condition, with $C_{C R} / C_{I N}$ ratios significantly less than 1.00 .
}

However several plasma determinations are necessary for 24 hour studies because of significant fluctuations in plasma "creatinine" concentration. In five subjects the plasma "creatinine" concentration varied as much as 10 per cent in four hours. In one subject the variation was as high as 17 per cent. In two the plasma concentrations were perfectly level throughout 24 hours, and in eight the variations were approximately 5 per cent or less. These changes in concentration have no direct correlation with variations in $\mathrm{C}_{\mathrm{CR}}$ and hence the plasma concentration curve of "creatinine" may not be used as an indication of changing glomerular activity. The reason for the variations in plasma concentration is not apparent. It is probably related to fluctuations in muscle metabolism, diet, blood volume, etc., as well as to changes in glomerular activity.

\section{CONCLUSIONS}

1. Diurnal variations of renal function were studied in 18 male adult patients without evidence of cardiovascular-renal disease by means of a constant intravenous infusion technique employing p-aminohippurate and inulin as test substances.

2. The mean night to day (N/D) ratios in these subjects for urine flow was $0.83 \pm 0.38$, for inulin $\mathrm{U} / \mathrm{P}$ ratio, $1.40 \pm 0.41$, for inulin clearance, $0.96 \pm 0.07$, for endogenous "creatinine" clearance, $0.97 \pm 0.06$ and for $\mathrm{PAH}$ clearance, 0.98 \pm 0.06 , indicating a significant decrease in urine flow, a considerable increase in tubular reabsorption of water, and a relatively constant glomerular filtration rate and renal plasma flow during the night as a whole. However, during the four hour period from 12 midnight to 4:00 A.M., corresponding to the period of deepest sleep there is a slight but significant fall in glomerular filtration; not in renal plasma flow. The decrease in urine flow at night is almost wholly attributable to increased tubular reabsorption of water.

3. Good agreement between the endogenous "creatinine" and inulin clearances was obtained throughout 24 hours. The average $\mathrm{C}_{\mathrm{CR}} / \mathrm{C}_{\mathrm{IN}}$ ratio was $0.95 \pm 0.10$. Significant variations in the plasma endogenous "creatinine" concentrations may occur throughout the day and night which exceed the changes to be expected from changes in filtration rate, assuming constant creatinine production. Plasma levels of "creatinine" should be 
obtained at four to six hour intervals if the endogenous "creatinine" clearance is to be used to measure glomerular activity throughout a 24 hour period or longer.

4. The renal extraction of PAH in two subjects after a 24 hour infusion of this substance was 0.903 and 0.930 , indicating the validity of $\mathrm{C}_{\mathbf{P A B}}$ as a measure of effective renal plasma flow after prolonged infusion.

6. The mean peak values for glomerular filtration rate and effective renal plasma flow in patients allowed water $a d l i b$, but not hydrated prior to observation, were $119 \pm 23$ and $597 \pm 124$ cc./min. per 1.73 sq. m., respectively. These values are considerably lower than the usually accepted ones of $131 \pm 22$ and $697 \pm 136 \mathrm{cc} . / \mathrm{min}$. per 1.73 sq. m. obtained during short period observations in the post-absorptive state and after hydration.

\section{BIBLIOGRAPHY}

1. Kleitman, N., Physiology of sleep. I. The effects of prolonged sleeplessness on man. Am. J. Physiol., 1923, 66, 67.

2. Simpson, G. E., Diurnal variations in the rate of urine excretion for two hour intervals: some associated factors. J. Biol. Chem., 1924, 59, 107.

3. Simpson, G. E., The effect of sleep on urinary chlorides and $\mathrm{pH}$. J. Biol. Chem., 1926, 67, 505.

4. Manchester, R. C., The diurnal rhythm in water and mineral exchange. J. Clin. Invest., 1933, 12, 995.

5. Simpson, G. E., Changes in the composition of urine brought about by sleep and other factors. J. Biol. Chem., 1929, 84, 393.

6. Norn, M., Untersuchungen über das Verhalten des Kaliums im Organismus. II. Über Schwankungen der Kalium-, Natrium-, und Chloridausscheidung durch die Niere im Laufe des Tages. Skandin. Arch. f. Physiol., 1929, 55, 184.
7. Brod, J., Klincský uýżnam filtrace a resorpee v ledvinách. (Clinical significance of filtration and reabsorption in the kidneys.) Čas. lék. čes., 1946, 85, 1315.

8. Fishberg, A., Hypertension and Nephritis. Lea and Febiger, Philadelphia, 1939, Ed. 9.

9. Fishberg, A., Heart Failure. Lea and Febiger, Philadelphia, 1940, Ed. 2.

10. Breed, E., and Schreiner, G., Personal communication.

11. Graubard, D. J., Robertazzi, R. W., and Peterson, M. C., A method for accurately measuring the rate of flow of intravenous fluids. Anesthesiology, 1947, 8, 372.

12. Earle, D. P., Jr., and Berliner, R. W., A simplified clinical procedure for measurement of glomerular filtration rate and renal plasma flow. Proc. Soc. Exper. Biol. \& Med., 1946, 62, 262.

13. Peterson, L. H., A method for introduction and use of a flexible plastic arterial catheter of small diameter. Federation Proc., 1947, 6, 179.

14. Ladd, M., and Schreiner, G., Plastic tubing as a means of administering intravenous fluids in man. In press, New England J. Med.

15. Warren, J. V., Brannon, E. S., and Merrill, A. J., Method of obtaining renal venous blood in unanesthetized persons with observations on extraction of oxygen and sodium para-amino hippurate. Science, 1944, 100, 108.

16. Bradley, S. E., and Bradley, G. P., The effect of increased intra-abdominal pressure on renal function in man. J. Clin. Invest., 1947, 26, 1010.

17. Goldring, W., and Chasis, H., Hypertension and Hypertensive Disease. The Commonwealth Fund, New York, 1944.

18. Bonsnes, R. W., and Taussky, H. H., On the colorimetric determination of creatinine by the Jaffe reaction. J. Biol. Chem., 1945, 158, 581.

19. Smith, H. W., Finkelstein, N., Aliminosa, L., Crawford, B., and Graber, M., The renal clearances of substituted hippuric acid derivatives and other aromatic acids in dog and man. J. Clin. Invest., 1945, 24, 388.

20. Brod, J., and Sirota, J. H., The renal clearance of endogenous "creatinine" in man. J. Clin. Invest., $1948,27,645$. 